\title{
Neuropathological Changes in Chronic Adult Hydrocephalus: Cortical Biopsies and Autopsy Findings
}

\author{
Marc R. Del Bigio, Erico R. Cardoso and William C. Halliday
}

\begin{abstract}
Background: The cortical changes resulting from chronic hydrocephalus in adults are not well defined. Methods: Retrospective analysis of twenty-one patients (age 64-88 years) with a clinical diagnosis of "normal pressure hydrocephalus" who underwent cortical biopsy at the time of intracranial pressure monitoring or shunt insertion, and eight patients who were biopsied but not shunted. Eleven brains (age 26-92 years), seven from patients who could be considered to have "normal pressure hydrocephalus", were also examined following autopsy. Age- and sex-matched control brains with small ventricles and no history of dementia were compared to the hydrocephalic brains. Senile plaques and neurofibrillary tangles were assessed semiquantitatively and a non-parametric statistical analysis was employed. Results: Five biopsies exhibited both senile plaques and rare neurofibrillary tangles, while two had only neurofibrillary tangles. Neurofibrillary tangles were more prevalent in hydrocephalic brains than in controls. There was no difference in the prevalence of senile plaques between the two groups. Grumose bodies in the substantia nigra were identified in five autopsy brains, a prevalence higher than in control brains. Conclusions: These pathological features are not specific for hydrocephalus; however, they suggest that long-standing ventriculomegaly is associated with degenerative brain changes in sites beyond the periventricular white matter. The presence of senile plaques in cortical biopsies from hydrocephalic patients does not appear to be a contraindication to shunting; however a prospective study in patients undergoing intracranial pressure monitoring would better address the issue.
\end{abstract}

RÉSUMÉ: Changements neuropathologiques dans l'hydrocéphalie chronique chez l'adulte: biopsies corticales et observations faites à l'autopsie. Introduction: Les changements corticaux consécutifs à l'hydrocéphalie chronique chez l'adulte sont mal définis. Méthodes: Nous présentons une analyse rétrospective de vingt-et-un patients (âgés de 64 à 88 ans) chez qui un diagnostic clinique d'hydrocéphalie normotensive avait été posé et qui ont subi une biopsie corticale au moment du monitorage de la pression intracrânienne ou lors de la mise en place d'une dérivation, et de huit patients chez qui on a fait une biopsie mais sans dérivation. Onze cerveaux (âge de 26 à 92 ans), dont sept provenant de patients qui pourraient être considérés comme présentant une hydrocéphalie normotensive, ont été examinés lors d'une autopsie. Des cerveaux contrôles appariés pour l'âge et le sexe dont les ventricules étaient petits et qui provenaient de patients ne présentant pas d'histoire de démence ont été comparés à des cerveaux hydrocéphales. Les plaques séniles et les amas neurofibrillaires ont été évalués semiquantitativement et les données ont été analysées au moyen d'une méthode statistique non-paramétrique. Résultats: Cinq biopsies présentaient des plaques séniles et de rares amas neurofibrillaires et deux n'avaient que des amas neurofibrillaires. Les amas neurofibrillaires étaient plus prévalents dans les cerveaux hydrocéphales que dans les cerveaux contrôles. Il n’y avait pas de différence dans la prévalence des plaques séniles entre les deux groupes. Des corps grumeleux ont été identifiés dans la substance noire de cinq cerveaux provenant d'autopsies de patients, une prévalence plus élevée que dans les cerveaux contrôles. Conclusions: Ces observations anatomopathologiques ne sont pas spécifiques de l'hydrocéphalie. Cependant elles évoquent la possibilité qu'une ventriculomégalie de longue durée est associée avec des changements dégénératifs du cerveau dans des sites qui sont au-delà de la substance blanche périventriculaire. La présence de plaques séniles dans les biopsies corticales de patients présentant une hydrocéphalie ne semble pas être une contre-indication à la mise en place d'une dérivation. Cependant une étude prospective chez des patients qui subissent un monitorage de la pression intracrânienne serait plus adéquate pour répondre à cette question.

Can. J. Neurol. Sci. 1997; 24: 121-126

Pathological changes in the cerebral cortex of adult humans with chronic hydrocephalus are not well documented. ${ }^{1}$ Cortical biopsies have infrequently been performed when cerebrospinal fluid (CSF) shunts were placed in patients with the "normal pressure hydrocephalus" syndrome (NPH). Two reports concerning a total of twenty patients documented no abnormalities in patients who responded to shunting, while Alzheimer's disease-type changes were associated with a poor response to shunt. ${ }^{2,3}$ More recently, among eighteen patients undergoing frontal biopsy at time of shunting for NPH, four had Alzheimertype abnormalities, two had evidence of cerebrovascular disease, and three had "non-specific degenerative changes". ${ }^{4}$ That there may be increased prevalence of neurofibrillary tangles in hydrocephalic cerebral cortex was first suggested by Wisniewski and coworkers in an abstract, the details of which are not published to our knowledge. ${ }^{5}$ We have attempted to define whether chronic hydrocephalus in the adult predisposes to the development of

From the Department of Pathology, University of Manitoba and Health Sciences Centre, Winnipeg, (MD, WH) and Department of Neurosurgery, Brookdale Hospital Medical Center, Brooklyn, NY (EC)

RECEIVED AUGUST 23, 1996. ACCEPTED IN FINAL FORM JANUARY 6, 1997.

Reprint requests to: Marc R. Del Bigio, Department of Pathology, University of Manitoba, D212 - 770 Bannatyne Avenue, Winnipeg, Manitoba, Canada R3E 0W3 
neurofibrillary tangles or senile plaques. Twenty-one cortical biopsies from adults undergoing a CSF shunt procedure for hydrocephalus and eleven autopsy brains from hydrocephalic patients were compared to age and sex-matched controls.

\section{Patients and Methods}

Adult patients with suspected NPH referred to a single neurosurgeon (EC) were studied retrospectively. All had gait disturbance, urinary incontinence, and/or dementia (at least $2 / 3$ features), with gait disturbance being the overshadowing complaint, and a CT scan showing ventriculomegaly. All patients or their guardian gave full consent for subsequent studies and procedures, and the project was approved by the local Hospital Ethics Committee.

Patients and their relatives were interviewed and examined by the same physician. Follow-up clinical examinations were performed 3 and 12 months after shunting. Pre- and post-operatively patients had a mental state examination consisting of orientation to person place and time, immediate and short term recall, knowledge of current events, serial subtraction of 7 from 100 , and ability to reverse a series of digits. Gait was assessed for fluidity, balance, and speed by visual inspection. Sixteen patients with a tentative diagnosis of NPH underwent intracranial pressure monitoring. ${ }^{6}$ At the time of catheter insertion a biopsy of the cerebral cortex was performed. Eight patients with altered CSF pressure dynamics underwent a ventriculoperitoneal shunting procedure with a low pressure valve 1-8 weeks later. The other eight patients whose intracranial pressure dynamics did not meet the criteria for NPH were not shunted. Following loss of funding for the cerebral hydrodynamics testing, the diagnosis of NPH was made on clinical and radiological criteria alone. Thirteen patients undergoing a shunt procedure had a biopsy of the posterior parietal cortex at the site of shunt insertion. During the period of study, 13 additional patients were diagnosed with NPH and shunted but refused consent for biopsy.

Biopsy tissue (approximately $1 \mathrm{~mm}$ diameter by $2-19 \mathrm{~mm}$ long) was immersion fixed in $10 \%$ buffered formalin. Paraffinembedded sections $(6 \mu \mathrm{m})$ were stained with hematoxylin and eosin, modified Bielschowsky method, ${ }^{7}$ and Congo red on 7-10 serial levels and each was examined independently by two observers. Because the biopsies were not of regular size and could not be precisely matched to a control area we did not attempt strict quantification. We assessed senile plaques (defined as "those with thickened silver-positive neurites") using the semiquantitative scale of "sparse" $(+)$, "moderate" $(++)$, or "frequent" (+++) proposed by the Consortium to Establish a Registry for Alzheimer's Disease (CERAD).$^{8}$ Diffuse plaques were not included. At 100x ocular magnification the biopsies occupied $1 / 2$ to $2 / 3$ of the field. With biopsies of this size, "frequent" plaques were obvious, however, "sparse" plaques might be missed. Intracytoplasmic silver-positive neurofibrillary tangles were searched for at $400 \mathrm{x}$ ocular magnification and graded as "+" if one or more were found or " ++ " if more than one per high power field $(400 \mathrm{x})$ were identified. In no case were the findings in the biopsy specimen used to guide the decision to shunt.

Eleven brains retrieved at autopsy from hydrocephalic adults were also studied. None of these patients was biopsied during life. Patients 3, 6, 7, 8, 9 were studied by us in entirety. For the other six, only photographs of the brains and paraffin-embedded tissues were available. In all cases the hospital records were reviewed in detail. The criteria for inclusion were a) active hydrocephalus diagnosed during life with or without shunting, or b) ventriculomegaly identified at autopsy in the absence of other abnormalities that would cause cerebral atrophy. Moderate ventriculomegaly is defined as ventricular enlargement with septum to mid-caudate distance of $2-4 \mathrm{~cm}$; severe ventriculomegaly is defined as ventricular enlargement with extreme thinning of the cerebral mantle to less than $2.5 \mathrm{~cm}$ at any point or septum to mid-caudate distance of $>4 \mathrm{~cm}$. All cases were specifically examined for pathological changes in the periventricular region, deep white matter and cerebral cortex (particularly at sites of maximal thinning), hippocampus, basal ganglia, structures surrounding the third ventricle and cerebral aqueduct, and substantia nigra. All sections were examined using hematoxylin and eosin staining; Luxol fast blue or solochrome cyanine was used to stain myelin and the modified Bielschowsky method was used to identify senile plaques and neurofibrillary tangles, which were graded in the same manner as in the biopsy specimens. Marchi staining was performed on samples of maximally thinned periventricular white matter in 5 patients. Immunohistochemical staining using anti-GFAP (Biogenex; 1/100 dilution) was used to assess reactive astrogliosis, anti-neurofilament (Biogenex; 1/200 dilution) was used to assess periventricular axons, and anti-HLA-DR (Dako; 1/200 dilution) was used to assess microglial reaction.

Control cases, chosen from our autopsy cases, were age and sex-matched to both surgical and autopsy patients. None of the controls had any documented history of dementia or neurodegenerative disorder (causes of death included cardiac events, sepsis, and acute trauma). None had ventricular enlargement evident at the time of brain cutting. The cortical site to be assessed was matched to the site of the surgical biopsy. We did not try to precisely match the size of the area searched for senile plaques and neurofibrillary tangles to the size of the somewhat irregular biopsies. We studied an area approximately $10 x$ larger in control tissues than in surgical specimens and accepted that there would be a greater likelihood of finding plaques and tangles in the control cases; thus the hypothesis that hydrocephalus is associated with these types of neurodegenerative changes could be subject to Type I error. In the case of autopsies, plaque and tangle comparisons were made in the frontal lobe at the coronal level of the head of the anterior commissure, approximating the site at which biopsies were taken in the first subset of the surgical group. For statistical comparisons, the plaque score was expressed as a number from $0-3$ and the tangle score was as a number from $0-2$. Wilcoxon signed rank test for paired nonparametric data was used to compare the data.

\section{Results}

\section{Clinical Data}

The data for 21 patients undergoing shunting for NPH are summarized in Table 1. Patient age ranged from 64-88 years. Four patients had a potentially related prior history of trauma, subarachnoid hemorrhage, or meningitis. Five patients had Parkinsonian symptoms in addition to their other findings. 
Seven patients had a history of hypertension. Five patients were unimproved after shunting, 9 exhibited minor improvement of functional status ("good" outcome) usually with regard to gait and incontinence, and 7 had substantial or complete resolution of symptoms ("very good" or "excellent" outcome respectively). Beneficial response to shunting was observed in $4 / 4$ patients with a relevant past history and $3 / 5$ patients with Parkinsonian symptoms. Two patients developed chronic subdural hematomas and one patient developed an abducens palsy after shunting. Seven patients are known to have died but none of their brains was obtained for autopsy study.

Table 1: Hydrocephalic patients undergoing cerebral biopsy at time of ICP monitoring or shunting (a).

\begin{tabular}{lccccc}
\hline Patient & Age / sex & $\begin{array}{c}\text { CT findings } \\
\text { (b) }\end{array}$ & $\begin{array}{c}\text { Plaques } \\
\text { (c) }\end{array}$ & $\begin{array}{c}\text { Tangles } \\
\text { (d) }\end{array}$ & $\begin{array}{c}\text { Outcome of } \\
\text { shunt (e) }\end{array}$ \\
\hline 1 & $80 \mathrm{M}$ & $\mathrm{V}, \mathrm{A}$ &,$++ \mathrm{B}$ & ++ & $\mathrm{G}$ \\
\hline 2 & $72 \mathrm{M}$ & $\mathrm{V}, \mathrm{A}$ & - & - & $\mathrm{G}$ \\
\hline $3(\mathrm{f})$ & $72 \mathrm{M}$ & $\mathrm{V}$ &,$++ \mathrm{C}$ & + & $\mathrm{VG}$ \\
\hline 4 & $76 \mathrm{M}$ & $\mathrm{V}, \mathrm{A}$ & - & - & $\mathrm{G}$ \\
\hline 5 & $82 \mathrm{M}$ & $\mathrm{V}, \mathrm{P}, \mathrm{A}$ & - & - & $\mathrm{G}$ \\
\hline 6 & $68 \mathrm{~F}$ & $\mathrm{~V}$ & - & - & $\mathrm{G}$ \\
\hline 7 & $68 \mathrm{~F}$ & $\mathrm{~V}$ & $+++\mathrm{C}$ & + & $\mathrm{NI}$ \\
\hline 8 & $68 \mathrm{M}$ & $\mathrm{V}, \mathrm{P}$ & - & - & $\mathrm{E}$ \\
\hline 9 & $73 \mathrm{~F}$ & $\mathrm{~V}, \mathrm{P}, \mathrm{A}$ & - & + & $\mathrm{VG}$ \\
\hline 10 & $88 \mathrm{M}$ & $\mathrm{V}$ & - & - & $\mathrm{G}$ \\
\hline 11 & $68 \mathrm{~F}$ & $\mathrm{~V}$ & - & - & $\mathrm{G}$ \\
\hline 12 & $73 \mathrm{~F}$ & $\mathrm{~V}, \mathrm{~A}$ &,$++ \mathrm{C}$ & + & $\mathrm{VG}$ \\
\hline 13 & $77 \mathrm{~F}$ & $\mathrm{~V}$ & - & + & $\mathrm{E}$ \\
\hline 14 & $64 \mathrm{M}$ & $\mathrm{V}, \mathrm{I}$ & - & - & $\mathrm{G}$ \\
\hline 15 & $85 \mathrm{M}$ & $\mathrm{V}, \mathrm{P}$ & - & - & $\mathrm{NI}$ \\
\hline 16 & $78 \mathrm{~F}$ & $\mathrm{~V}, \mathrm{~A}$ &,$++ \mathrm{B}$ & + & $\mathrm{NI}$ \\
\hline 17 & $78 \mathrm{M}$ & $\mathrm{V}, \mathrm{P}$ &,$+ \mathrm{A}$ & - & $\mathrm{VG}$ \\
\hline 18 & $85 \mathrm{M}$ & $\mathrm{V}$ & - & - & $\mathrm{NI}$ \\
\hline 19 & $87 \mathrm{~F}$ & $\mathrm{~V}, \mathrm{P}, \mathrm{A}$ & - & - & $\mathrm{G}$ \\
\hline 20 & $77 \mathrm{~F}$ & $\mathrm{~V}, \mathrm{~A}$ & - & - & $\mathrm{VG}$ \\
\hline 21 & $65 \mathrm{~F}$ & $\mathrm{~V}, \mathrm{~A}$ & - & - & $\mathrm{NI}$ \\
\hline & & & & &
\end{tabular}

Footnotes for Table 1.

a) Patients 1-8 underwent ICP monitoring and anterior frontal lobe biopsy at that time, patients 9-21 underwent posterior parietal lobe biopsy at time of shunting.

b) CT scan data include ventriculomegaly (V), atrophy (A), old infarcts (I), and periventricular lucency (P).

c) Semiquantitative senile plaque grading based on CERAD criteria, + sparse, ++ moderate, +++ frequent; letter grade corresponds to the agerelated plaque score.

d) Neurofibrillary tangle counts, + if one or more seen, ++ if more than one per $40 \mathrm{x}$ high power field.

e) Results of shunting after 12 months- no improvement (NI); some functional improvement, good $(\mathrm{G})$; significant functional improvement, very good (VG); returned to normal, excellent (E).

f) Patient 4 was paraplegic as a result of a motor vehicle accident 33 years prior to presentation.

The clinical and pathological features of the eleven autopsy cases are summarized in Table 2. Five of eleven patients (\# 1,3, $5,9,11)$ were elderly with clinical features typical of NPH. Four of the eleven patients had long-standing hydrocephalus with mild head enlargement secondary to a congenital defect; two of these had chronic gait symptoms similar to those found in the NPH syndrome $(\# 8,10)$, the other two patients were mentally retarded $(\# 2,7)$. The remaining two patients were unusual; one was a schizophrenic (Patient \#4) with severe rigidity who after death was found to have severe ventriculomegaly with disrupted septum pellucidum; the other a man who presented with headaches and unsteadiness at age 23 years and was found to have "aqueductal stenosis" with moderate ventriculomegaly (Patient \#6). Twenty-seven years later, following two shunt revisions, he died of a malignant astrocytoma in the midbrain. Five of the 11 patients were shunted and four responded well. One patient with NPH (Patient \#5) died too soon after shunting to assess the response. Two NPH patients (\#1 and 9) died within 2 months of shunting.

Among the eleven autopsy brains, examination of the cerebral cortex revealed five with senile plaques (two had, in addition, innumerable diffuse plaques), five with rare intracytoplasmic neurofibrillary tangles, four with microvascular changes secondary to hypertension, and two with foci of neuronal loss and reactive gliosis (Table 2). In addition, the substantia nigra of $5 / 11$ patients had grumose bodies, as many as six on a single section (Figure 1). A sixth patient had intracytoplasmic neurofibrillary tangles in the periaqueductal region, particularly in neurons of the oculomotor nucleus. Only $1 / 32$ autopsy patient controls had any grumose bodies in the substantia nigra. Furthermore, in our recent autopsy experience of eighty unselected brains from adults over age 50 years, only four had grumose bodies; among these, two had Alzheimer's disease and the other two had multiple cerebral infarcts.

\section{Analysis of neurofibrillary tangles and senile plaques in comparison to control cases}

Among the 21 biopsies from shunted patients, five exhibited both rare intracytoplasmic neurofibrillary tangles and senile plaques, two had only scattered tangles, and one had only rare plaques. Of the five patients who did not respond to shunting, three had normal biopsies.

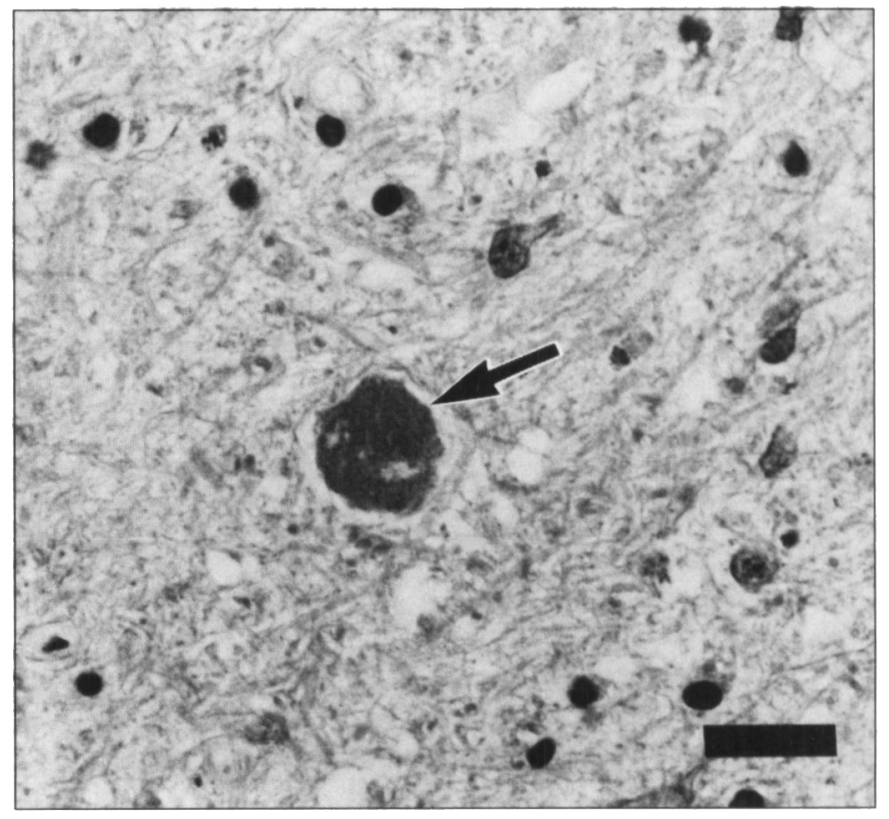

Figure 1: Photomicrograph showing a large grumose body (arrow) with slightly granular appearance in the substantia nigra pars reticularis of autopsy Patient 9. There is a paucity of pigmented neurons at this site. Hematoxylin and eosin. Bar $=20 \mu \mathrm{m}$. 
Table 2: Summary of neuropathological findings in autopsy patients.

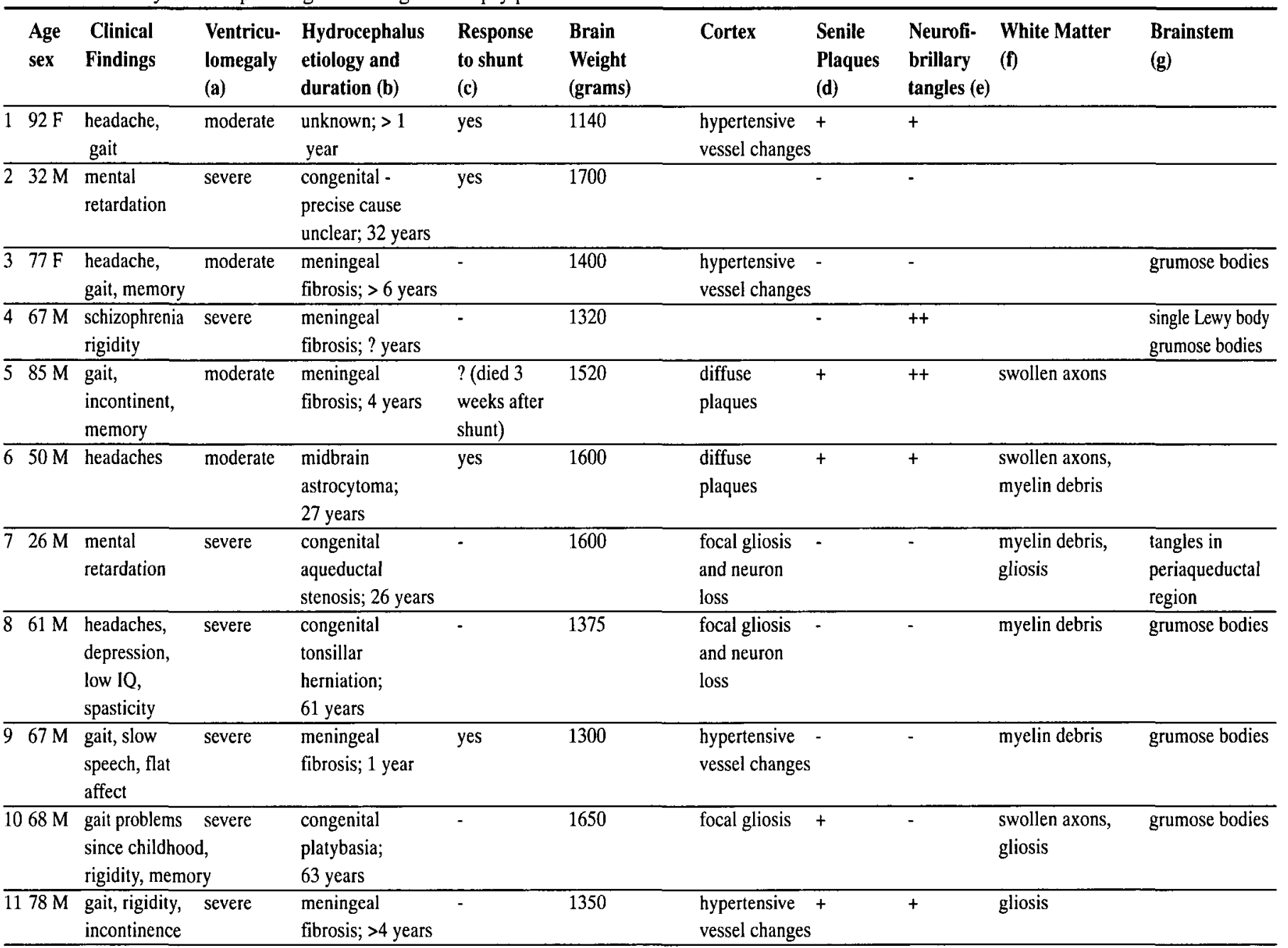

Footnotes for Table 2 .

a) Ventriculomegaly was judged on CT scan prior to shunt or at time of brain cutting for unshunted patients. Moderate indicates a septum to mid-caudate distance of $2-4 \mathrm{~cm}$, and severe is $>4 \mathrm{~cm}$.

b) For hydrocephalus type "Congenital" refers to onset early in childhood. The estimated duration of hydrocephalus is based on the history of symptoms.

c) Patients 1, 2, 5, 6, and 9 were shunted. A response is considered to be any improvement in clinical status. Patient 5 died too soon after shunting to make a valid judgment.

d) Semiquantitative assessment of senile plaques (neuritic type) in the lateral frontal cortex as defined by CERAD criteria.

e) Neurofibrillary tangles in lateral frontal cortex,+ if one or more found, ++ if more than one per $40 \mathrm{x}$ high power field.

f) Periventricular white matter changes. Gliosis is mentioned only if a dense band extended beyond 2 mm from the ventricle surface. Myelin debris was identified by Marchi staining which was not done in all cases.

g) Lewy bodies, grumose bodies, or pale-staining neurons were observed in the substantia nigra. Neurofibrillary tangles were observed in several sites in the periaqueductal region.

Chi square analysis was performed on $2 \times 2$ contingency table comparing the presence or absence of neurofibrillary tangles to the response or non-response following shunting. There was no significant relationship between the presence of plaques or tangles and response to shunting (chi square $=0.13 ; 1$ d.f.; $p=0.72$ ). Even $2 / 3$ patients with an age-related senile plaque score of " $\mathrm{C}$ " as defined by CERAD criteria responded well to shunting. Congophilic angiopathy was detected in one biopsy (Patient 12).

Eight patients underwent ICP monitoring and frontal lobe biopsy but were not shunted. Four met the ICP criteria for diagnosis of NPH but refused shunt. One of these had no plaques or tangles, the other three had rare neurofibrillary tangles and an age-related senile plaque score of "C". Four other patients did not exhibit any abnormalities on ICP monitoring and were not shunted. Among these, two had no plaques or tangles, the other two had age-related senile plaque scores of "A" and "C". Overall, among biopsied patients with suspected $\mathrm{NPH}$, neurofibrillary tangles were more prevalent in the frontal 
cortex $(8 / 16)$ than in the parieto-occipital cortex (4/13).

Patients who might reasonably be diagnosed with chronic adult NPH syndrome were pooled. This included 21 biopsy specimens from shunted patients, 4 biopsy specimens from patients who refused shunts, and 9 autopsy specimens with NPH syndrome or chronic hydrocephalus in adulthood (the two mentally retarded patients were excluded). Among the hydrocephalic patients $15 / 34$ had neurofibrillary tangles, compared to 6/34 age and sex-matched controls. This difference was significant according to the statistical analysis $(p=0.0269)$. There was no apparent relationship between the duration of hydrocephalus (to the best of our ability to estimate this on the basis of symptoms) and the presence of neurofibrillary tangles. Senile plaques were found in 14/34 hydrocephalic patients and 11/34 controls. The difference was not statistically significant $(\mathrm{p}=0.375)$. Statistical comparison including all biopsied patients and controls did not yield a different conclusion ( $p=0.0081$ for tangles; $p=0.247$ for senile plaques).

\section{DisCussion}

Three decades after the initial description of the "normal pressure hydrocephalus" (NPH) syndrome, accurate prediction of a beneficial response to shunting remains imprecise. Furthermore, the name of this syndrome is found to be inaccurate; the term "idiopathic adult hydrocephalus syndrome" has been suggested. ${ }^{9}$ Patients most likely to respond to shunting have a short history of gait disorder, not overshadowed by dementia, and studies suggestive of hydrodynamic abnormalities. ${ }^{10}$ Arterial hypertension appears to be a risk factor for $\mathrm{NPH} .{ }^{11-14}$ Our understanding of the neuropathological changes in NPH remains incomplete. Leptomeningeal and arachnoid granulation fibrosis may contribute to impaired CSF flow. ${ }^{15,16}$ Myelin loss, axonal damage, accumulation of myelin debris, and gliosis in periventricular white matter are well recognized sequelae of chronic hydrocephalus in adults (not necessarily with the classic NPH syndrome)..$^{1,17,18}$ The cerebral cortex and other brain areas have been only infrequently studied in chronic adult hydrocephalus. ${ }^{19}$

We studied cerebral biopsies from twenty-nine patients with a clinical diagnosis of NPH, as well as the brains of eleven hydrocephalic patients, five of whom presented with typical NPH and two others with NPH-like features due to long-standing congenital hydrocephalus. ${ }^{20}$ An obvious shortcoming of this retrospective study is the heterogeneity of patients, with regard to method of diagnosis, management, and tissue available for examination. Questions remain concerning how episodic alterations in intracranial pressure and cerebral blood flow might differentially affect the frontal and parietal regions, particularly when one considers that the majority of hydrocephalic adults exhibit preferential frontal horn enlargement. ${ }^{1}$ Regardless, more hydrocephalic patients than controls exhibited typical neocortical intracytoplasmic neurofibrillary tangles, albeit in small quantity. A published abstract also reported that the brains of $14 / 30$ hydrocephalic adults with mental retardation had neurofibrillary changes. ${ }^{5}$ The presence of neurofibrillary tangles in the midbrain of our autopsy patient 7 is more unusual. Similar changes were observed in another severely retarded young adult with congenital hydrocephalus. ${ }^{21}$ It has been suggested that metabolic and oxidative stresses, which are known to occur in hydrocephalus, ${ }^{4,22}$ could contribute to neurofibrillary tangle formation. ${ }^{23}$

Senile plaques were equally prevalent (approximately $30 \%$ of patients) in hydrocephalic and age-matched control cases, as might be expected for an elderly population. ${ }^{24}$ Accordingly, the presence of senile plaques in biopsied cortex was not associated with a poor response to shunting as has been previously suggested. ${ }^{2}$ Some patients with Alzheimer's disease can present with NPH-like signs and symptoms; however in these patients dementia is the prevalent feature. ${ }^{25-28}$ We did not attempt to define whether the plaques in hydrocephalic patients were qualitatively different than in the control population. ${ }^{29}$ Two of our autopsy patients, one of whom was only 50 years old, had abundant diffuse plaques in the cortex. It has been hypothesized that diffuse plaques may represent a generalized end response to brain injury. ${ }^{30,31}$ It is evident that more severe injury to the cortex can occur, as illustrated in our two autopsy patients with very severe ventriculomegaly associated with focal loss of neurons and pancortical astrogliosis. ${ }^{32-35}$

With the exception of atrophy in corticospinal tracts passing through the cerebral peduncles and medullary pyramids, pathological alterations in the brainstem due to hydrocephalus are not well documented. ${ }^{1}$ We were surprised by the grumose bodies in the substantia nigra of $5 / 11$ hydrocephalic brains. Four patients were elderly with the NPH syndrome. The fifth patient was a schizophrenic who, in addition, had a single Lewy body in the substantia nigra. Grumose bodies in the substantia nigra are observed in a variety of degenerative brain disorders, Parkinson's disease being a notable exception. ${ }^{38,39}$ The nature of these structures is not entirely understood. They are thought to be astrocytic inclusions, perhaps related to phagocytosis of local degenerative material. ${ }^{39}$ Rare Lewy bodies have been observed in 4-5\% of brains from individuals without clinical Parkinson's disease and might in some cases represent a non-specific result of nigral damage. ${ }^{36,37}$ Patients with hydrocephalus not uncommonly present with Parkinsonism. ${ }^{40}$ Eight patients in this report had rigidity or tremor. Parkinsonism in hydrocephalic patients has generally been attributed to striatal dysfunction, and pathological changes in the substantia nigra could represent a retrograde degenerative phenomenon.

In summary, chronic hydrocephalus in adults, in particular with the NPH syndrome, may be associated with subtle degenerative processes in cerebral cortex, including neurofibrillary tangle formation. Degenerative changes may also occur in the substantia nigra. While the changes reported here are not specific for hydrocephalus, they suggest that chronic untreated hydrocephalus might be harmful to brain structures beyond the periventricular white matter. The cause of cortical and brainstem changes could be a combination of direct mechanical stresses, retrograde degeneration due to axonal injury, and chronic metabolic stresses. ${ }^{1,22}$ A prospective trial in hydrocephalic patients undergoing intracranial pressure monitoring would be needed to determine if cortical biopsy is of any value in predicting which patients will respond to shunting.

\section{ACKNOWLEDGEMENT}

We thank Dr. J. Bilbao for allowing us to examine two of the autopsy patients in detail. 


\section{REFERENCES}

1. Del Bigio MR. Neuropathological changes caused by hydrocephalus. Acta Neuropathol 1993; 85: 573-585.

2. Stein SC, Langfitt TW. Normal pressure hydrocephalus: predicting the results of cerebrospinal fluid shunting. J Neurosurg 1974; 41: 463-470

3. Torack RM. Adult dementia: history, biopsy, pathology. Neurosurgery $1979 ; 4: 434-442$.

4. Tedeschi E, Hasselbach SG, Waldemar G, et al. Heterogenous cerebral glucose metabolism in normal pressure hydrocephalus. J Neurol Neurosurg Psychiatry 1995; 59: 608-615.

5. Wisniewski HM, Popovitch ER, Kaufman MA, Wisniewski KE. Neurofibrillary changes in advanced hydrocephalus. A clinicopathological study. J Neuropathol Exp Neurol 1987; 46: 340.

6. Cardoso ER, Piatek D, Del Bigio MR, Stambrook M, Sutherland JB. Quantification of abnormal intracranial pressure waves and isotope cisternography for diagnosis of occult communicating hydrocephalus. Surg Neurol 1989; 31: 20-27.

7. Lamy C, Duyckaerts C, Delaere P, et al. Comparison of seven staining methods for senile plaques and neurofibrillary tangles in a prospective series of 15 elderly patients. Neuropathol Appl Neurobiol 1989; 15: 563-578.

8. Mirra SS, Heyman A, McKee D, et al. The Consortium to Establish a Registry for Alzheimer's Disease (CERAD). Part II. Standardization of the neuropathologic assessment of Alzheimer's disease. Neurology 1991; 41: 479-486.

9. Kristensen B, Malm J, Fagerlund M, et al. Regional cerebral blood flow, white matter abnormalities, and cerebrospinal fluid hydrodynamics in patients with idiopathic adult hydrocephalus syndrome. J Neurol Neurosurg Psychiatry 1996; 60: 282-288.

10. Vanneste JAL. Three decades of normal pressure hydrocephalus: are we wiser now? J Neurol Neurosug Psychiatry 1994; 57: 1021-1025.

11. Bradley WG, Whittemore AR, Watanabe AS, et al. Association of deep white matter infarction with chronic communicating hydrocephalus: implications regarding the possible origin of normalpressure hydrocephalus. Am J Neuroradiol 1991; 12: 31-39.

12. Earnest MP, Fahn S, Karp JH, Rowland LP. Normal pressure hydrocephalus and hypertensive cerebrovascular disease. Arch Neurol 1974; 31: 262-266.

13. Krauss JK, Regel JP, Vach W, et al. Vascular risk factors and arteriosclerotic disease in idiopathic normal-pressure hydrocephalus of the elderly. Stroke 1996; 27: 24-29.

14. Newton H, Pickard JD, Weller RO. Normal pressure hydrocephalus and cerebrovascular disease: findings of postmortem. J Neurosurg Psychiatry 1989; 52: 804.

15. DeLand FH, James AE, Ladd DJ, Konigsmark BW. Normal pressure hydrocephalus: a histologic study. Am J Clin Pathol 1972; 58: 58-63.

16. Vessal K, Sperber EE, James AE. Chronic communicating hydrocephalus with normal CSF pressures: a cisternographic-pathologic correlation. Ann Radiol (Paris) 1974; 17: 785-793.

17. Di Rocco C, Di Trapani G, Maira G, et al. Anatomo-clinical correlations in normotensive hydrocephalus. Reports on three cases. $\mathrm{J}$ Neurol Sci 1977; 33: 437-452

18. Russell DS. Observations on the pathology of hydrocephalus. Med Res Council Special Report Ser 1949; 265: 1-138.

19. Brusa G, Piccardo A, Pizio N, Gambini C. Anatomopathological study of dementia syndrome linked with an abnormal cerebrospinal fluid flow. Report of literature and personal observations. Pathologica 1991; 83: 351-358.
20. Graff-Radford NR, Godersky JC. Symptomatic congenital hydrocephalus in the elderly simulating normal pressure hydrocephalus. Neurology 1989; 39: 1596-1600.

21. Fan KJ, Pezeshkpour G. Neurofibrillary tangles in association with congenital hydrocephalus. J Nat Med Assoc 1987; 79: 1001$1003,1006$.

22. Chumas PD, Drake JM, Del Bigio MR, Da Silva M, Tuor UI. Anaerobic glycolysis preceding white-matter destruction in experimental neonatal hydrocephalus. J Neurosurg 1994; 80: 491-501.

23. Blass JP, Gibson GE. The role of oxidative abnormalies in the pathophysiology of Alzheimer's disease. Rev Neurol 1991; 147: 513-525

24. Mann DMA, Brown AMT, Prinja D, Jones D, Davies CA. A morphological analysis of senile plaques in the brains of nondemented persons of different ages using silver, immunocytochemical and lectin histochemical staining techniques. Neuropathol Appl Neurobiol 1990; 16: 17-26.

25. Ball MJ, Neurofibrillary tangles in the dementia of "normal pressure" hydrocephalus. Can J Neurol Sci 1976; 3: 227-235.

26. Ball MJ, Vis CL. Relationship of granulovacuolar degeneration in hippocampal neurones to aging and to dementia in normal-pressure hydrocephalus. J Gerontol 1978; 33: 815-824.

27. Bret $P$. L'hydrocephalie chronique de l'adulte. Neurochirurgie 1990; 36 Suppl 1: 1-159.

28. de Mol J, Retif J, Brihaye J. Démence hydrocephalique et/ou dégénerative. Acta Neurol Belg 1989; 89: 228-235.

29. Wang D, Munoz DG. Qualitative and quantitative differences in senile plaque dystophic neurites of Alzheimer's disease and normal aged brain. J Neuropathol Exp Neurol 1995; 54: 548-556.

30. Gearing M, Mirra SS, Hedreen JC, et al. The Consortium to Establish a Registry for Alzheimer's Disease (CERAD). Part X. Neuropathology confirmation of the clinical diagnosis of Alzheimer's disease. Neurology 1995; 45: 461-466.

31. Popovitch ER, Wisniewski HM, Barcikowska M, et al. Alzheimer neuropathology in non-Down's syndrome mentally retarded adults. Acta Neuropathol 1990; 80: 362-367.

32. Orton ST. A pathological study of a case of internal hydrocephalus. Am J Insanity 1908; 65: 229-278.

33. Penfield W. Notes on cerebral pressure atrophy. Res Publ Assoc Nerv Ment Dis $1929 ; 8$ : 246-362.

34. Pierce LB. Aquired hydrocephalus. Report of two cases occurring in adults. Am J Psychiatr 1933; 12: 769-773.

35. Yakovlev PI. Paraplegias of hydrocephalus. (A clinical note and interpretation). Am J Mental Deficiency 1947; 51: 561-576.

36. Oppenheimer DR, Esiri MM. Diseases of the basal ganglia, cerebellum and motor neurons. In: Adams JH, Duchen LW, eds. Greenfield's Neuropathology, 5th Edition. New York: Oxford University Press, 1992: 988-1045.

37. Wenning G, Quinn N. Are Lewy bodies non-specific epiphenomena of nigral damage? Mov Disord 1994; 9: 378-379.

38. Arai N, Yagishita S, Amano N, Iwabuchi K, Misugi K. "Grumose degeneration" of Tretiakoff. J Neurol Sci 1989; 94: 319-323.

39. Arai N. Grumose or foamy spheroid bodies involving astrocytes in the human brain - review. Neuropathol Appl Neurobiol 1995; 21: $238-245$

40. Curran T, Lang AE. Parkinsonian syndromes associated with hydrocephalus: case reports, a review of the literature, and pathophysiological hypothesis. Mov Disord 1994; 9: 508-520. 